\title{
Generalized ILVEN or Blaschkoid Psoriasis: A Persistent Dilemma
}

\author{
Kaushal A, Gahalaut P, Mishra N, Rastogi MK
}

Department of Dermatology, Venereology and Leprosy, Shri Ram Murti Smarak Institute of Medical Sciences, Bareilly

\begin{abstract}
A 24-year-old man presented with itchy verrucous, scaly red-brown papules, \& linear plaques distributed in a blaschkoid pattern all over the body since last 20 years associated with itching. A skin biopsy was consistent with ILVEN (inflammatory linear verrucous epidermal nevus). Histopathologically, it can be difficult to distinguish it from linear psoriasis. It may respond to conventional anti-psoriatic therapies like potent topical corticosteroids applied under occlusion, or systemic treatments like acitretin.
\end{abstract}

Key words: Interleukin-1; Isotretinoin; Mosaicism; Nevus; Psoriasis

\section{Introduction}

1 nflammatory linear verrucous epidermal nevus (ILVEN) is a pruritic, erythematous scaly lesion following Blaschko's lines \& characterized by an eczematous or psoriasiform papules variable length, occasionally extending the whole length of a limb. The main differential diagnosis is Blaschkoid psoriasis. The pathogenesis of ILVEN is not clear, but it could be explained by the well-established concept of genetic mosaicism.

\section{Case report}

A 24 years old male presented with 20 years history of pruritic, non-discharging, erythematous, papulosquamous and verrucous lesions all over the body (Figure-1), (Figure-2). It was revealed by the patient that since onset, the lesions were persistent and confined to the same sites. However, the lesions never cleared up completely and responded to different treatment partially or temporarily. There was no history of injury or any other previous eruption at the site of present lesions. There was no history of psoriasis or any other skin disease in the family.

The lesions were arranged along blaschko lines (Type $1 a$ - narrowband) all over the anterior abdominal wall and anterolateral aspect of bilateral thighs, bilateral arms, and back. No other dermatological lesions were present at any other site of the body. Scaling was

\section{Address of Correspondence}

Dr. Apurva Kaushal

Junior resident

Department of dermatology

Shri Ram Murti Smarak Institute of Medical Sciences, Bareilly

E-mail:apurva10may@gmail.com present in the frontal portion of the scalp. His nails and oral mucosa were spared. There was no joint involvement. Systemic examination did not reveal any abnormality. Anti Human Immunodeficiency Virus antibodies were negative and routine laboratory investigations were within normal limits.

Histopathology of the lesions was consistent with ILVEN (Figure - 3). Sections show thickened stratum corneum comprising of parakeratosis focally containing few neutrophils and orthokeratotic hyperkeratosis. Epidermis shows irregular hyperplasia and shows hypogranulosis beneath zones of parakeratosis with focal hypergranulosis beneath orthokeratotic hyperkeratosis. Upper dermal perivascular lymphocytic infiltrate with few neutrophils is present.

He responded partially to Isotretinoin $40 \mathrm{mg}$ daily along with topical steroids \& keratolytics. The erythema subsided and scaling became less marked. He was advised to have regular follow-ups but lost to follow up in 2 months.

Submitted: $20^{\text {th }}$ December 2018

Accepted: $15^{\text {th }}$ February 2019

Published: 31 $1^{\text {st }}$ March 2019

How to cite this article

Kaushal A, Gahalaut P, Mishra N, Rastogi MK. Generalized ILVEN or blaschkoid psoriasis: A persistent dilemma. Nepal Journal of Dermatology, Venereology and Leprology. 2019;17(1):79-82. doi: http://dx.doi. org/ 10.3126/njdvl.v17i1.22048

Licensed under CC BY 4.0 International License which permits use, distribution and reproduction in any medium, provided the original work is properly cited. 

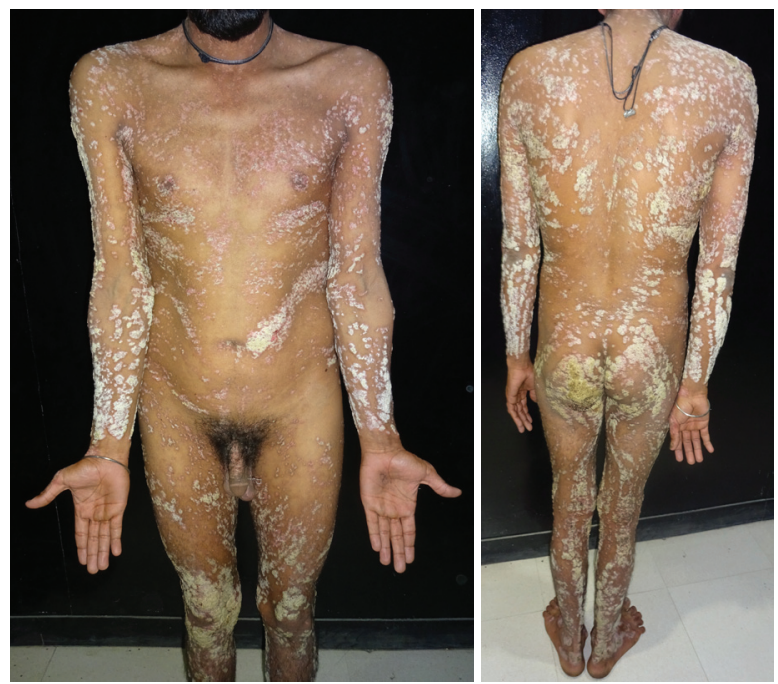

Figure 1, 2: Multiple erythematous linear scaly plaques on the body along the lines of blaschko

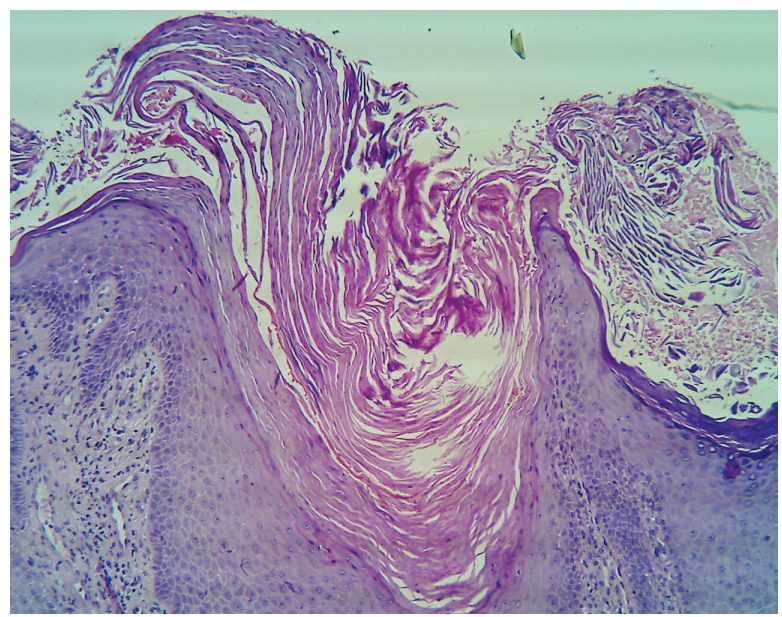

Figure 3: Haematoxylin and Eosin stain: (10X) photomicrograph showing hyperplastic epidermis having alternating ortho and parakeratotic areas with depressed hypergranular epidermis overlaid by orthokeratosis.

\section{Discussion}

In 1896, the term inflamamatory linear verrucous epidermal nevus (ILVEN) was proposed by Unna. ${ }^{1}$ Blaskoid psoriasis is a rare form of psoriasis first described in 1951. ${ }^{2}$ In 1971, Altman and Mehregan proposed clinical criteria for ILVEN which was later modified by Morag and Metzker in 1985..$^{3.4}$

1. Clinical - typical linear verrucous morphology accompanied by intense pruritus

2. Early age of onset.

3. Histology - a psoriasiform picture, inflammatory elements, and alternating areas of parakeratosis and agranulosis

4. Resistance to therapy.

Dupre and Cristol described histopathological criteria for diagnosing ILVEN in $1977 .{ }^{5}$ Our patient complied with the modified clinical criterion. However, there is a diagnostic dilemma between ILVEN and linear psoriasis. Few Authors had described the differences based on clinical feature, histopathology and immunohistopathology between the two entities enlisted in Table-1 ${ }^{6-9}$

The cause and pathogenesis of ILVEN are unknown however due to sporadic nature, rare familial cases and similarity with other nevi, it was thought to be the result of a new and early postzygotic mutation reflecting genetic mosaicism. ${ }^{10}$ According to Happle, ILVEN might reflects the activity of a transposable element that is partly expressed and partly silenced at an early developmental stage. ${ }^{11}$ ILVEN is also thought to be associated with upregulation of interleukin 1 , interleukin 6, tumor necrosis factor-[alpha], and intercellular adhesion molecule $1 .^{12}$ Infection may be a trigger for the clonal inflammation in ILVEN. ${ }^{13}$

Table 1:

\begin{tabular}{|c|c|c|}
\hline Features & ILVEN & Blaschkoid psoriasis \\
\hline History & $\begin{array}{l}\text { Soon after birth (first month of life), Slowly } \\
\text { progressive, pruritic }\end{array}$ & Late onset, rapid progression, slighty itchy \\
\hline Clinical & Verrucous, thick, scaly. & Silvery white scaling, nail involvement \\
\hline Histopathology & $\begin{array}{l}\text { Classical- Hypergranulosis \& parakeratosis } \\
\text { alternating with hypogranulosis \& } \\
\text { orthokeratosis }\end{array}$ & $\begin{array}{l}\text { Hyperkeratosis ,parakeratosis, absence } \\
\text { of granular layers, an elongation of rete } \\
\text { ridges, suprapapillary thinning \& munro's } \\
\text { microabscesses }\end{array}$ \\
\hline $\begin{array}{l}\text { Immuno } \\
\text { histopathology }\end{array}$ & $\begin{array}{l}\text { 1.involucrin increased in orthokeratotic regions } \\
\text { deficient in parakeratotic regions } \\
\text { 2. Ki-67-positive nuclei reduced, } \\
\text { 3. a focal pattern in anti-keratin } 16 \\
\text { 4.a homogenous pattern of anti-keratin } 10\end{array}$ & $\begin{array}{l}\text { 1.suprabasal keratinocytes express Involucrin. } \\
\text { 2.elastase positive cells -more significant, } \\
\text { 3.a homogenous pattern of anti-keratin } 16 \\
\text { 4.a focal / diminished pattern of anti-keratin } 10\end{array}$ \\
\hline Treatment & $\begin{array}{l}\text { Refractory to anti psoriatic therapy. Surgical } \\
\text { excision definitive treatment. }\end{array}$ & Responds to anti psoriatics \\
\hline
\end{tabular}


Hofer hypothesized that like psoriasis, ILVEN may also represent segmental types 1 and 2 mutation. ${ }^{14} \mathrm{He}$ described four different groups of diseases to define precisely the correlation between ILVEN and linear psoriasis.

- $\quad$ ILVEN with or without concomitant psoriasis, who responded only a part to antipsoriatic treatment.

- ILVEN without concomitant psoriasis, who had good response to antipsoriatic treatment.

- linear psoriasis with psoriasis vulgaris,

- linear psoriasis without concomitant psoriasis

The last three subtypes responds well to anti psoriatic treatment. Our patient represents a generalised ILVEN, which has no psoriasis and no response to treatment that is why can be categorized as first ILVEN entity by Hofer.

Like common forms of localized psoriasis, unilateral psoriasis along blaschko lines respond to topical

\section{References}

1. Unna PG. The histopathology of the diseases of the skin. New York: Macmillan; 1876.p.1148.

2. Leslie G. Linear psoriasis. $\mathrm{Br} J$ Dermatol.1951;63: 262-3.https://doi. org/10.1111/j.1365-2133.1951.tb13723.x

3. Altman J, Mehregan $\mathrm{AH}$. Inflammatory linear verrucose epidermal nevus. Arch Dermatol. 1971;104(4):385-9. https://doi.org/10.1001/ archderm.104.4.385

4. Morag C, Metzker A. Inflammatory linear verrucous epidermal nevus: report of seven new cases and review of the literature. Pediatr Dermatol. 1985;3(1):15-8. https://doi.org/10.1111/j.1525-1470.1985. tb00479.x

5. Dupre A, Christol B. Bilateral inflammatory linear verrucous epidermal nevus localized on the lip and with minimal histological lesions. Ann Dermatol Venereol. 1977;104:163-4.

6. Saraswat A, Sandhu K, Shukla R, Handa S. Unilateral linear psoriasis with palmoplantar, nail, and scalp involvement. Pediatr Dermatol. 2004;21:70-3. https://doi.org/10.1111/j.07368046.2004.21116.x

7. Ito M, Shimuzu N, Fujiwara H, Maruyama T, Tezuka M. Histopathogenesis of inflammatory linear verrucous epidermal naevus. Arch Dermatol Res. 1991; 283:491-9. https://doi.org/10.1007/ BF00371921 steroids, keratolytics and calcipotriol, but only temporarily. ${ }^{15}$

If available, immunohistochemical studies should be carried out to differentiate such lesions from inflammatory linear verrucous epidermal naevus, but it was not carried out as the patient couldn't bear the expenses of the test.

\section{Conclusion}

This case is being reported for its rarity \& widespread distribution \& to revisit the concept of genetic mosaicism. Biopsy \& immunohistochemical studies are needed to confirm the diagnosis \& patient counselling should be done appropriately.

Financial disclosure: None.

Conflict of interest to disclosure: None declared.

8. Jong $E$, Rulo HF, Kerkhof PC. Inflammatory linear verrucous epidermal nevus versus linear psoriasis. A clinical, histological and imunnohistochemical study. Acta Derm Venereol. 1991;71:343-6.

9. Vissers WH, Muys L, Erp PE, de Jong EM, van de Kerkhof PC. Immunohistochemical differentiation between inflammatory linear epidermal naevus (ILVEN) and psoriasis. Eur J Dermatol. 2004;14:216-20.

10. Welch ML, Smith KJ, Skelton HG, Frisman DM, Yeager J, Angritt $P$ et al. Immunohistochemical features in inflammatory linear verrucous epidermal nevi suggest a distinctive pattern of clonal dysregulation of growth. Military Medical Consortium for the Advancement of Retroviral Research. J Am Acad Dermatol. 1993;29: 242-8. https://doi.org/10.1016/01909622(93)70175-S

11. Happle R. Transposable elements and the lines of Blaschko: A new perspective. Dermatology. 2002;204:4-7.https://doi. org/10.1159/000051801

12. Lee BJ, Mancini AJ, Renucci J, Paller AS, Bauer BS. Full -thickness surgical excision for the treatment of inflammatory verrucous epidermal nevus. Ann Plast Surg 2001:47:285-92 https://doi.org/10.1097/00000637-20010900000011

13. Sotiriadis D, Patsatsi A, Lazaridou E, Kastanis A, Devliotou-Panagiotidou D. Is inflammatory linear verrucous epidermal naevus a form of linear 
naevoid psoriasis? J Eur Acad Dermatol Venereol, 2006:20:483-4. https://doi.org/10.1111/j.14683083.2006.01481.x

14. Hofer T. Does inflammatory linear verrucous epidermal nevus represent a segmental type 1/type 2 mosaic of psoriasis?
Dermatology 2006;212:103-7. https://doi. org/10.1159/000090648

15. De Jong $E$, Rulo $H F$, van de Kerkhof PC: Inflammatory linear verrucous epidermal naevus (ILVEN) versus linear psoriasis. A clinical, histological and immunohistochemical study. Acta Derm Venereol. 1991;71:343-46. 